\title{
Involving junior doctors in medical article publishing: is it an effective method of teaching?
}

\author{
Samson O Oyibo \\ Department of Diabetes \& \\ Endocrinology, Peterborough City \\ Hospital, Peterborough, UK
}

This article was published in the following Dove Press journal:

Advances in Medical Education and Practice

22 September 2017

Number of times this article has been viewed

Background: Having peer-reviewed articles published in medical journals is important for career progression in many medical specialties. Despite this, only a minority of junior doctors have the skills in the area of medical article publishing. The aim of this study was to assess junior doctors' views concerning being involved in medical article publishing and whether they perceive involvement as an effective method of teaching.

Methods: A cross-sectional survey was administered to a convenience sample of doctors who had been involved in medical article publishing. Questions concerned training and involvement in publishing as junior doctors, effects on education and training, is it an effective method of teaching and should publishing be part of their education and training program. Questions used the 5-point Likert scale. Of the 39 doctors, 37 (94.9\%) doctors responded.

Results: Only one-third of respondents agreed that they had adequate training or involvement in medical article publishing during their undergraduate medical training. Many (78.4\%) agreed that it was difficult to get published as a junior doctor. Publishing as a junior doctor improved knowledge about publishing, understanding of the topic and interest in the field of study for 92 , 92 and $73 \%$ of respondents, respectively. Many (89\%) agreed that publishing made them eager to publish more. Most (76\%) agreed that it was likely to encourage interest in a postgraduate career in that field of study. A majority $(92 \%)$ felt that involvement in medical article publishing is an effective method of teaching and it should be a part of the junior doctors' education and training program.

Conclusion: Junior doctors feel that involvement in medical article publishing contributes to learning and education and is an effective method of teaching. This supports the need to incorporate such training into the junior doctors' education and training program.

Keywords: medical publishing, effective teaching, junior doctor education, cross-sectional survey

\section{Introduction}

Having peer-reviewed articles published in medical journals (full articles, case reports, abstracts and so on) is very important for career progression in many medical specialties. ${ }^{1}$ There is a perception that doctors with peer-reviewed publications demonstrate a greater commitment to their specialty and their desire to pursue their area of specialist interest. ${ }^{2}$ Although enhancement of their curriculum vitae has been cited as a motivation to be involved in medical article publishing, interest in the subject has been cited as a more important reason by junior doctors. ${ }^{3}$ Despite this, the principles of academic writing and medical publishing are rarely formally taught at medical school and only a minority of junior doctors have the knowledge and skills in the area of medical article publishing.

Correspondence: Samson O Oyibo Department of Diabetes \& Endocrinology, Peterborough City Hospital, Bretton Gate, Peterborough PE3 9GZ, UK

Tel $+44 I 733678000$

Fax +44 1733676787

Email samoyibo@yahoo.co.uk 
Medical article publishing entails much more than just writing an article. Writing case reports entails finding an interesting case, doing a literature search, collating medical information, choosing a journal and writing up an interesting case and responding to reviewers' comments. ${ }^{4}$ Writing audit/research reports as abstracts or full articles requires involvement in conception and design, acquisition, analysis and interpretation of data, as well as drafting and editing the article. ${ }^{5}$ By the time a junior doctor has gone through these steps it is hoped that knowledge around that particular topic/field of study would be enhanced. There are published journal-specific instructions and other literature concerning how to get published, but only few particularly directed at teaching junior doctors the necessary skills for medical article publishing. ${ }^{6}$ Additionally, this form of education is not formally part of the junior doctors' education and training program.

We believe that involving junior doctors in medical article publishing not only encourages interest in that particular field of study but also encourages interest in academic growth and career progression, whether it is in the academic institution or at the point of patient care. Despite some institutions actively involving junior doctors in medical article publishing (full articles, abstracts, case reports and so on) as authors/ coauthors for several years now, there is a scarcity of studies evaluating the effect of this activity on junior doctors' education and training and whether it is perceived by junior doctors as an effective method of teaching. Therefore, the aim of this study was to assess junior doctors' views concerning being involved in medical article publishing during junior doctor training, the education and training benefits and whether they perceive being actively involved in medical article publishing during training as an effective method of teaching. The information obtained from this survey could be used as a basis to promote and design a medical article publishing training module that can be added to the junior doctors' education and training program.

\section{Methods}

\section{Study design}

A cross-sectional, anonymous, web-based survey was administered to a convenience sample of medical doctors who had been involved in medical article publishing (full articles, abstracts, case reports and so on) as authors/coauthors under our departmental supervision during their time as junior doctors over the last 7 years (2010-2016). This survey (questionnaire distribution and data collection) was carried out over the month of June 2017.

\section{Study participants}

Forty-two medical doctors had at least one peer-reviewed medical article publication (case reports, abstracts or full articles) under our departmental supervision during the period of their junior doctor training over the last 7-year period (2010-2016). An email was sent out to each doctor asking them whether they would like to participate in this survey and we received permission replies from 39 doctors. Ethics approval for this survey was sought through the Research \& Development department of our institute. This survey was deemed exempt from ethical approval on the account of it being registered with our Quality, Governance and Compliance Department as a Quality of Education Improvement Project. Participants were assured of strict anonymity and confidentiality during this survey.

\section{Questionnaire and administration}

The survey questionnaire was prepared online using a well-known and established survey company called SurveyMonkey. ${ }^{7}$ The questionnaire contained 10 questions, which concerned previous training, and involvement in medical article publishing during their undergraduate medical training, the experience obtained from their involvement in medical article publishing as a junior doctor, whether this involvement provided education and training benefits, whether they perceived active involvement in medical article publishing as an effective method of teaching and whether they thought training skills in medical article publishing should be included in the junior doctors' education and training program. Each question required an answer using the 5-point Likert scale (strongly agree, agree, neither agree or disagree, disagree and strongly disagree). There were no previously published or validated questionnaires available that would cater for the purpose of this study, so this one was created from scratch as a pilot for this survey.

A web-link to the survey was sent via email to the participants, and they were given a month within which to complete the survey. An email reminder was also sent to all participants 2 weeks into the 1-month survey period.

\section{Sample size}

Thirty-nine doctors gave their consent to take part in this survey and so received the web-link. In return, we received 37 completed questionnaires, giving us a response rate of $94.9 \%$.

\section{Data analysis}

The data obtained from this survey were analyzed quantitatively by expressing the percentages (and whole numbers) 
of responses to each question on the Likert scale. To visually compare overall responses to the questions, the response options on the 5-point Likert scale mentioned earlier were given weighting scores (5, 4, 3, 2 and 1, respectively). For each question, the number of respondents who selected a particular response option was multiplied by the weighting score assigned to that response option. The sum total for all five response options produced a summative Likert score for that question. The summative Likert score was then divided by the total number of respondents to that question to produce a weighted average Likert score ranging from 5 meaning that a majority of respondents strongly agree with that question down to 1 meaning that a majority of respondents strongly disagree with that question. ${ }^{8}$

\section{Results}

Thirty-seven doctors took part in this pilot survey. The survey questions along with the corresponding Likert scale responses are listed in Table 1.

\section{Medical article publishing during undergraduate training}

Only $29.7 \%$ of respondents agreed (agreed or strongly agreed) that they had adequate training concerning medical article publishing during their undergraduate medical training. Additionally, only $35.1 \%$ of respondents agreed that they had adequate involvement in medical article publishing during their undergraduate medical training. In contrast, 59.5 and $54.1 \%$ of respondents disagreed with these two statements, respectively.

\section{Medical article publishing as a junior doctor}

The majority of respondents (78.4\%) agreed that it was difficult to get a medical article publication as a junior doctor. Only $8.1 \%$ of respondents disagreed (disagreed or strongly disagreed) with this statement.

\section{The impact on junior doctor education and training}

A majority of respondents (91.9\%) agreed that involvement in medical article publishing as a junior doctor improved their knowledge on how to get published, $91.9 \%$ of respondents agreed that it improved their understanding of that particular topic/field of study and $73 \%$ of respondents agreed that it increased their interest in that particular topic/field of study. In contrast, only 5.4, 2.7 and $5.4 \%$ of respondents disagreed with these three statements, respectively.

Table I Survey questions with corresponding Likert scale responses $(N=37)$

\begin{tabular}{|c|c|c|c|c|c|}
\hline \multirow[t]{2}{*}{ Questions } & \multicolumn{5}{|l|}{ Likert scale } \\
\hline & $\begin{array}{l}\text { Strongly } \\
\text { agree }\end{array}$ & Agree & $\begin{array}{l}\text { Neither agree } \\
\text { or disagree }\end{array}$ & Disagree & $\begin{array}{l}\text { Strongly } \\
\text { disagree }\end{array}$ \\
\hline $\begin{array}{l}\text { I had adequate training concerning medical article publishing during my } \\
\text { undergraduate medical training }\end{array}$ & $16.22 \%(6)$ & $13.51 \%(5)$ & $10.81 \%(4)$ & $40.54 \%(15)$ & $18.92 \%(7)$ \\
\hline $\begin{array}{l}\text { I had adequate involvement in medical article publishing during my } \\
\text { undergraduate medical training }\end{array}$ & $10.81 \%(4)$ & $24.32 \%(9)$ & $10.81 \%(4)$ & $27.03 \%(10)$ & $27.03 \%(10)$ \\
\hline $\begin{array}{l}\text { It is generally difficult to get a medical article publication as a } \\
\text { junior doctor }\end{array}$ & $|3.5| \%(5)$ & $64.86 \%(24)$ & $13.5 \mid \%(5)$ & $8.11 \%(3)$ & $0.00 \%(0)$ \\
\hline $\begin{array}{l}\text { Being involved in medical article publishing as a junior doctor } \\
\text { improved my knowledge on how to get published }\end{array}$ & $40.54 \%(15)$ & $51.35 \%(19)$ & $2.70 \%(I)$ & $5.41 \%(2)$ & $0.00 \%(0)$ \\
\hline $\begin{array}{l}\text { Being involved in medical article publishing as a junior doctor } \\
\text { improved my understanding of that particular topic/field of study }\end{array}$ & $48.65 \%(18)$ & $43.24 \%(16)$ & $5.41 \%(2)$ & $2.70 \%(I)$ & $0.00 \%(0)$ \\
\hline $\begin{array}{l}\text { Being involved in medical article publishing as a junior doctor } \\
\text { increased my interest in that particular topic/field of study }\end{array}$ & $37.84 \%(14)$ & $35.14 \%(13)$ & $21.62 \%(8)$ & $5.41 \%(2)$ & $0.00 \%(0)$ \\
\hline $\begin{array}{l}\text { Being involved in medical article publishing as a junior doctor made me } \\
\text { eager to be involved in doing more medical article publications }\end{array}$ & $29.73 \%(11)$ & $59.46 \%(22)$ & $10.81 \%(4)$ & $0.00 \%(0)$ & $0.00 \%(0)$ \\
\hline $\begin{array}{l}\text { Involving junior doctors in medical article publishing is likely to } \\
\text { encourage them to pursue a postgraduate career/training in that } \\
\text { topic/field of study }\end{array}$ & $32.43 \%(12)$ & $43.24 \%(16)$ & $16.22 \%(6)$ & $5.41 \%(2)$ & $2.70 \%(I)$ \\
\hline $\begin{array}{l}\text { Involving junior doctors in medical article publishing is an effective } \\
\text { method of teaching }\end{array}$ & $37.84 \%(14)$ & $51.35 \%(19)$ & $5.41 \%(2)$ & $5.41 \%(2)$ & $0.00 \%(0)$ \\
\hline $\begin{array}{l}\text { Developing skills in medical article publishing should be an integral part } \\
\text { of the junior doctors' education and training program }\end{array}$ & $48.65 \%(18)$ & $43.24 \%(16)$ & $8.11 \%(3)$ & $0.00 \%(0)$ & $0.00 \%(0)$ \\
\hline
\end{tabular}

Note: Results are percentages and whole number (n) of participants' responses to questions I-I0. 
The majority of respondents (89.2\%) agreed that being involved in medical article publishing as a junior doctor made them eager to want to be involved/coauthor more medical article publications (none of the respondents disagreed with this statement). Additionally, $75.7 \%$ of respondents agreed that involvement in medical article publishing was likely to encourage junior doctors to want to pursue a postgraduate career/training in that topic/field of study (only $8.1 \%$ of respondents disagreed with this statement).

\section{Medical article publishing as an effective method of teaching}

Again the majority of respondents (92.2\%) felt that involving junior doctors in medical article publishing was an effective method of teaching (5.4\% of respondents disagreed with this statement). And most importantly, $91.9 \%$ of respondents felt that developing skills in medical article publishing should be an integral part of the junior doctors' education and training program. None of the respondents disagreed with this statement.

\section{The weighted average Likert scores}

The weighted average Likert scores $(5,4,3,2$ and 1$)$ for each question are represented in Figure 1 for visual comparison. This demonstrates that the majority of the responses fell within the "disagree" to "neither agree or disagree" portion of the Likert scale for the first two questions concerning having had previous experience and previous involvement in medical article publishing during their undergraduate medical training. The graph also shows that the majority of responses fell within the "agree" portion of the Likert scale for the next eight questions concerning difficulty with getting publications as a junior doctor, the educational and training benefits of medical article publishing, whether they perceive it as an effective method of teaching and whether it should be included as an integral part of the junior doctors' education and training program.

\section{Discussion}

The overall results of this survey suggest that medical article publishing during junior doctor training contributes to learning and education, and it is perceived by a majority of junior doctors as an effective method of teaching. Additionally, they felt that training in medical article publishing should be incorporated into the junior doctors' education and training program. Our survey also revealed that a majority of junior doctors had not had adequate training or involvement in medical article publishing during their undergraduate medical training years, and it was generally difficult for them to get a medical article publication as a junior doctor.

There is nothing in the literature concerning the use of medical article publishing as a method of teaching for junior doctors. Nor is there any published assessment of its perceived effect on junior doctors' education and training. In a qualitative study based on comments/narratives from three medical students who published case reports as part of an existing case reporting program, the authors proposed important educational benefits in writing case reports, such as observation and pattern recognition, hypothesis-generating skills, understanding patient-centered care and writing skills. The authors also concluded that case report writing can be an effective teaching tool with a broad range of potential

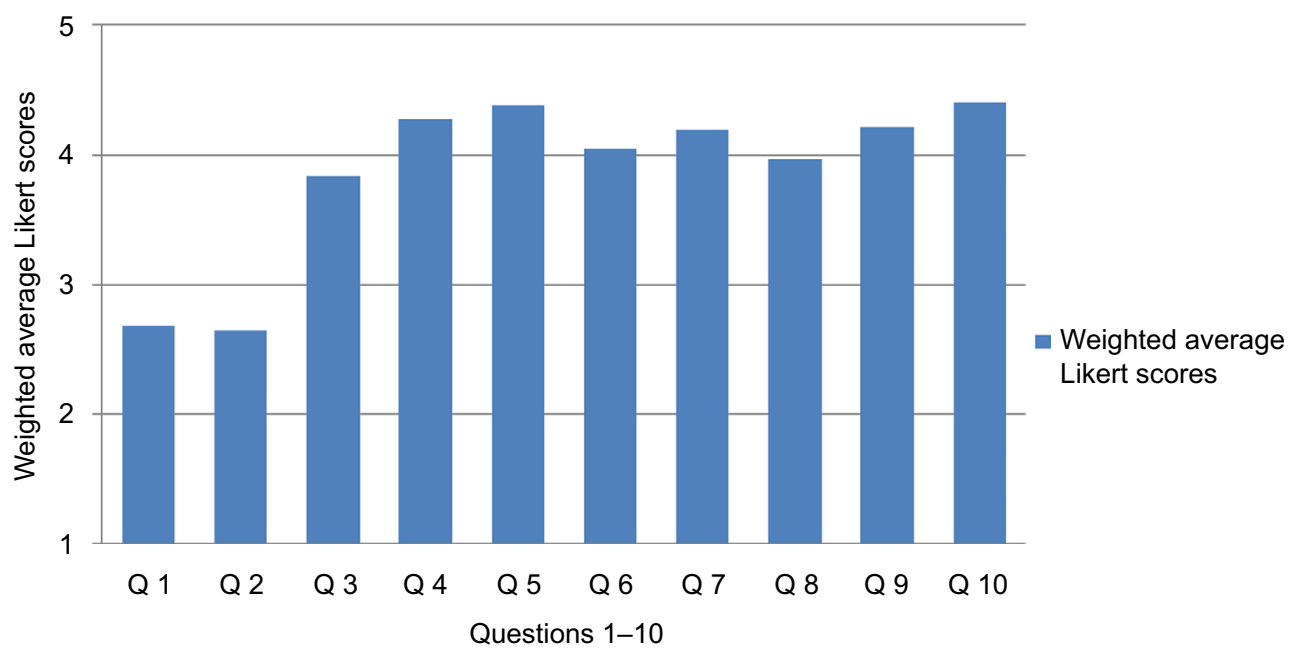

Figure I Graphical representation of the weighted average Likert score for each question.

Notes: The $X$-axis represents list of questions; $Y$-axis represents weighted average score on the Likert scale for each question (5, strongly agree; 4 , agree; 3 , neither agree nor disagree; 2 , disagree; I, strongly disagree). 
educational benefits. ${ }^{9}$ Writing up case reports gives rise to expertise in a particular condition or disease presentation, and being involved in medical article publishing as a trainee does demonstrate intellectual curiosity, a commitment to scientific inquiry and the ability to follow through on scholarly projects. ${ }^{10}$ Medical student involvement in research publications and whether it should be a mandatory core competency of the medical curriculum has been examined in some institutions. ${ }^{11}$ Medical students writing textbooks for students have found this involvement rewarding but emphasize the need for support from senior colleagues. ${ }^{12}$ Our survey is the first of its kind to examine the experience of junior doctors' involvement in medical article publishing and most importantly its use as an effective method of teaching.

The response rate to this survey was very good, despite it being well known that doctors are often a group with very low response rates to surveys in general. ${ }^{13-15}$ We think that this was because a notification/invitation email for permission was sent out beforehand and a reminder email was also sent out 2 weeks after the actual survey web-link was sent out. Additionally, the use of the web-based survey system may have been more convenient for most respondents, as opposed to paper surveys. Anonymity and strict confidentiality were also assured during this survey.

\section{Limitations to this study}

Despite the favorable response rate, there are important limitations to this pilot survey. First, this was just a small sample of the vast number of junior medical doctors in training, and therefore, larger surveys will be required to validate these results. Second, respondents were chosen based on the fact that they had a previous medical article publication during their period as a junior doctor. Further surveys should be carried out to assess the feelings of those junior doctors that have not been involved in medical article publishing. Third, the fact that all the respondents had a medical article publication under the same single departmental supervision could have introduced an element of response bias. However, this was a pilot survey and is the first of its kind involving junior doctors and medical article publishing. Fourth, although this survey looks at involvement in publishing during junior doctor training years, the first two questions in the questionnaire looked at previous experience during medical school training. It is possible that a significant number of participants may have graduated from medical schools that do not have research and publications as part of their training curriculum. Participants to this survey graduated from various medical schools around the world (a majority from the UK). This was a pilot survey based on a small sample size. The results cannot be generalized without a further large sample-sized survey.

\section{Future survey}

There had been no previous surveys carried out to explore junior doctors' experience around involvement in medical article publishing, so the questions used in this survey had to be created from scratch. We now need to create more questions that can be validated (construct, repeatability and internal reliability) so as to produce a more robust questionnaire. Questions should also explore the effects of different types of publications (eg, original research, reviews and case reports) on training and the effect of involvement in medical article publishing on better critical appraisal skills to evaluate published research in order to effectively practice evidence-based medicine. A qualitative approach should also be included to further evaluate the benefits of involvement in medical article publishing during junior doctor training.

\section{Conclusion}

This survey demonstrates the importance of medical article publishing for junior doctors' education and training. Larger surveys are required to capture the perception of all junior doctors as a whole. Involving junior doctors in at least one medical article publication every 2 years during their training will not only improve their curriculum vitae but also contribute to higher learning, career progression and critical appraisal skills to evaluate published papers. The results of this survey support the need to incorporate training in medical article publishing into the junior doctors' education and training program.

\section{Acknowledgment}

The author would like to thank all the doctors who participated in this study.

\section{Disclosure}

The author reports no conflicts of interest in this work.

\section{References}

1. McNeil A, Parkin CKE, Rubab U. Using a case report to teach junior doctors about medical publishing. Med Teach. 2007;29(5):511-511.

2. Grant P, Nwokolo M, Postlethwaite C. Essential and desirable: making the most of your postgraduate training. Clin Med. 2014;14(2):145-148.

3. Duffett R. Publication by junior doctors: why do they do it? Psychiatr Bull R Coll Psychiatr. 1994;18:553-554.

4. Sun Z. Tips for writing a case report for the novice author. JMed Radiat Sci. 2013;60(3):108-113.

5. International Committee of Medical Journal Editors [homepage on the Internet]. Recommendations for the Conduct, Reporting, Editing, and Publication of Scholarly Work in Medical Journals. 2017. [cited Dec 2016]. Available from: http://www.icmje.org. Accessed July 25, 2017. 
6. Natarajan A [webpage on the Internet]. What, where, and how to publish. BMJ Careers. 2017. [cited May 5, 2007]. http://careers.bmj.com/careers/ advice/What,_where,_and_how_to_publish. Accessed July 25, 2017.

7. Survey Monkey [homepage on the Internet]. Survey Monkey: Free Online Survey Software and Questionnaire Tool. 2017. Available from: https://www.surveymonkey.com. Accessed July 25, 2017.

8. Sullivan GM, Artino AR. Analyzing and interpreting data from Likerttype scales. J Grad Med Educ. 2013;5(4):541-542.

9. Packer CD, Katz RB, Lacopetti CL, Krimmel JD, Singh MK. A case suspended in time: the educational value of case reports. Acad Med. 2017;92(2):152-156.

10. Berger GN. Practical benefits of case reporting. In: Packer CD, Berger GN, Mookherjee S, editors. Writing Case Reports: A Practical Guide from Conception through Publication. Switzerland: Springer International Publishing; 2017:33-42.
11. Abu-Zaid A, Bamogaddam I, AlBader L, AlFakhri L, Nurhussen A. A call to encourage curricular research publications by medical students. Int J Med Educ. 2016;7:406.

12. Collins G, Davis J, Swift O. Publishing a medical book: authorship from a medical student perspective. Med Teach. 2015;37(1):100.

13. Cook JV, Dickinson HO, Eccles MP. Response rates in postal surveys of healthcare professionals between 1996 and 2005: an observational survey. BMC Health Serv Res. 2009;9:160.

14. Cunningham CT, Quan H, Hemmelgarn B, et al. Exploring physician specialist response rates to web-based surveys. BMC Med Res Methodol. 2015;15:32.

15. Beebe TJ, Locke GR, Barnes SA, Davern ME, Anderson KJ. Mixing web and mail methods in a survey of physicians. Health Serv Res. 2007;42(31): 1219-1234.

\section{Publish your work in this journal}

Advances in Medical Education and Practice is an international, peerreviewed, open access journal that aims to present and publish research on Medical Education covering medical, dental, nursing and allied health care professional education. The journal covers undergraduate education, postgraduate training and continuing medical education including emerging trends and innovative models linking education, research, and health care services. The manuscript management system is completely online and includes a very quick and fair peer-review system. Visit http://www.dovepress.com/testimonials.php to read real quotes from published authors.

Submit your manuscript here: http://www.dovepress.com/advances-in-medical-education-and-practice-journal 